\title{
Characteristics of interpersonal violence in adult victims at the Adult Emergency Trauma Centre (AETC) of Queen Elizabeth Central Hospital
}

\author{
Shabnam Sheikh ${ }^{1}$, Linda Chokotho ${ }^{2}$, Wakisa Mulwafu ${ }^{3}$, Mulinda Nyirenda ${ }^{4}, G_{r a c e}$ Le $^{5}$, Foster \\ Mbomuwa ${ }^{6}$, Hemant Pandit ${ }^{7}$, Chris Lavy ${ }^{7}$
}

1. Medical Officer, Queen Elizabeth Central Hospital.

2. Orthopedic Consultant, Beit Cure Hospital, Blantyre

3. Department of Surgery, College of Medicine, Blantyre.

4. Adult Emergency and Trauma Center and Clinics (Ambulatory Unit), Queen Elizabeth Central Hospital, Blantyre

5. Nuffield Department of Orthopaedics, Rheumatology and Musculoskeletal Sciences, University of Oxford

6. Beit Cure Hospital, Blantyre.

7. University of Oxford

\begin{abstract}
Introduction
Abstract

Globally, the burden of interpersonal violence and its significant impact on mortality, morbidity and disability makes it a major public health problem which necessitates intervention. This article examines characteristics of victims of interpersonal violence and violent events in Malawi. The focus is on a population that has been traditionally neglected in literature.

Methods

Queen Elizabeth Central Hospital $(\mathrm{QECH})$ maintains a trauma registry with data that is prospectively collected. Patients offered trauma care after interpersonal violence from May 2013 to May 2015 were evaluated.

Results

There were 1431 patients with violent events recorded at the Adult Emergency Trauma Centre (AETC) with a male predominance of $79.5 \%$. The dominant age group was young adults between 25-29 years old (22\%). Most attacks occurred during cold and dry season $(46.9 \%)$ and most common location was on the road (37.2\%). Alcohol use by victims was recorded in $10.5 \%$ of cases. Soft tissue injuries were the most common injuries sustained (74.1\%). Most patients were treated as outpatients $(80.9 \%)$. There were two deaths. At multivariate analysis, women had a lower risk of interpersonal violence as compared to men, (OR 0.82 [0.69-0.98]). Victims' use of alcohol was associated with increased risk of assault (OR 1.63 [1.27-2.10]). As compared to other places, odds of being assaulted were higher at home (OR 1.62 [1.27-2.06]) but lower at work (OR 0.68 [0.52-0.89) and on the road (OR 0.82 [0.65-1.03]). Odds of being assaulted were higher in the cold and dry season as compared to hot and dry season, (OR 1.26 [1.08-1.47]).

Conclusion

Young males were most involved in interpersonal violence. Location of injury and seasonal variation were significant factors associated with interpersonal violence and most commonly sustained injuries were soft tissue injuries. These findings will help in identifying targeted interventions for interpersonal violence in Malawi and other low-and-middle-income countries (LMICs).

Keywords: Interpersonal violence, Assault, Risk factors, low-and middle-income countries, Malawi
\end{abstract}

\section{Introduction}

Interpersonal violence is a global public health challenge that causes more than 1.3 million deaths worldwide each year, accounting for $2.5 \%$ of global mortality ${ }^{1}$. According to World Health Organization (WHO) 2014, for everyone who dies as a result of interpersonal violence, many more are injured and suffer from a range of physical, sexual, reproductive and mental health problems requiring hospital treatment ${ }^{1,2}$. More than $90 \%$ of the burden of interpersonal violence occurs in low- and middle-income countries $(\mathrm{LMICs})^{3}$. The associated interpersonal violence-related mortality and morbidity in LMICs is 2.5 times higher than in high-income countries, although rates vary between regions and even within countries ${ }^{3,4}$. In the year 2000 , interpersonal violence resulted in the disability or incapacitation of at least 6.2 million people on the African continent ${ }^{5}$.

The mortality rate associated with interpersonal violence in Malawi is 2.11 per 100,000 population ${ }^{6}$. According to a national survey in 2013, among Malawians aged 18 to 24 years old,
$42.4 \%$ of females and $64.5 \%$ of males reported experiencing some form of physical interpersonal violence prior to the age of 18. Additionally, from those who reported experiencing any physical interpersonal violence, $78.8 \%$ of females and $88.2 \%$ of males reported experiencing multiple incidents of physical interpersonal violence ${ }^{7}$. However, similar to other African regions, there is a paucity of published data on the risk factors associated with interpersonal violence in Malawi. Besides the toll of human misery, interpersonal violence exacts social and economic costs which may be substantial, though hard to quantify. Some of the direct economic costs of interpersonal violence are provision of treatment, mental health services, emergency care and criminal justice response, whereas the indirect costs include reduced economic productivity due to victims experiencing unemployment, absenteeism or poor job performance due to health problems or long-term disability related to the interpersonal violence. Globally, interpersonal violence is estimated to cost between $\$ 95$ - 163 billion a year?. A study by the Institute for 
Economics and Peace (IEP) states that, as Africa's biggest economy, South Africa has the highest interpersonal violence containment costs ( $\$ 51.2$ billion), and has one of the biggest interpersonal violence containment budgets in the world 17 th, globally out of 152 countries $^{10,11}$. Violence, as defined by WHO, is the intentional use of physical force or power, threatened or actual, against oneself, another person, or against a group or community, that either results in or has a high likelihood of resulting in injury, death, psychological harm, mal-development or deprivation ${ }^{12}$. It is categorized as self-directed, interpersonal or collective violence. The focus of our study is on interpersonal violence - a category of violence that includes harmful acts perpetrated by an individual or small group (such as a gang) against a family member (as in domestic violence), community member, friend, acquaintance or stranger ${ }^{12}$.

Violent behavior is provoked by a complex interaction of physiological, psychological and environmental factors. There are characteristics of individuals and their surrounding environment that increase the risk that he or she will perpetrate or experience interpersonal violence. There are different frameworks that are employed to understand these risk factors and the most common is the ecological model, employed predominantly within the public health approach. The model outlines factors at the individual, interpersonal, community and society levels: At the individual level, gender and age are key risk factors. One's age and gender are associated with greater or lesser propensity for involvement in interpersonal violence. For example, vulnerability to interpersonal violence changes over the life cycle; youth have the highest propensity to perpetrate or be victimized by interpersonal violence, but the elderly are also vulnerable to interpersonal violence. Young men are most vulnerable as both perpetrators and victims of interpersonal violence ${ }^{13}$. Alcohol or substance use is another major risk factor that influences interpersonal violence at an individual level ${ }^{12}$. The interpersonal level focuses on an individual's relationship with peers, intimate partners and family members. The community level examines and seeks to identify settings/ locations with high prevalence of interpersonal violence and the characteristics of these locations that increase the risk of interpersonal violence. Lastly, the societal level looks at the cultural norms, gender and economic inequality that give rise to interpersonal violence in a society ${ }^{12,13}$.

According to a cross-cultural study focusing on war, socialization and interpersonal violence; societies with higher incidence of active or historical armed conflicts and civil strife have an increased prevalence of interpersonal violence. ${ }^{14}$ Studies show that war-related trauma exposure correlates positively with aggression and enhanced levels of community and family violence ${ }^{13,15}$.

Sub-Sahara Africa has had the highest number of armed conflicts and injuries resulting from collective violence have been concentrated in sub-Saharan Africa ${ }^{5,16}$. However, unlike other countries in sub-Saharan Africa, Malawi, since its independence from the British colonial rule in 1964, has not experienced internal armed conflict or civil war ${ }^{17}$.

The aim of this paper is to identify some of the characteristics associated with interpersonal violence using the ecological model, which will help in identifying targeted interventions to reduce interpersonal violence in Malawi.

\section{Setting}

Queen Elizabeth Central Hospital (QECH) is a tertiary referral centre for the southern region of Malawi. A new adult emergency department called the Adult Emergency Trauma Centre (AETC) at QECH opened in October 2011. Along with trauma cases, the AETC treats both surgical and medical emergencies. The unit maintains a trauma registry with data that is prospectively collected. Patients offered trauma care after interpersonal violence from May 2013 to May 2015 were evaluated.

\section{Data Capture Form}

A 2 page data capture trauma registry form was developed. The form captured demographic information, mechanism of injury information, relevant medical history and examination (primary and secondary survey) findings, injury type and location, treatment offered and disposition of patients.

\section{Personnel and Training}

Consultative meetings were held with AETC clinicians who had been using the existing trauma care sheet to discuss how trauma data collection could be organized in the department. They recommended the addition of clerks to capture patient demographic information and mechanism of injury data while the clinicians would continue to enter clinical, injury diagnosis, management and disposition information.Ten clerks working in AETC underwent training on how to complete the trauma data form. All clinicians working in AETC also underwent training to ensure competency in completing the form.

To ensure validity of the collected data, throughout the two year period of data collection, the entire process of data collection was supervised by a medically qualified specialist who was in charge of the unit. To maintain reliability of data collection, regular meetings were held between the specialist and the data collection team to address and rectify any concerns raised regarding data collection.

\section{Data Collection and Entry}

The first section, which had demographic data, arrival information, injury information like time of injury and mechanism of injury was completed by data clerks. The second section, which had findings on primary and secondary survey, past medical history, clinical diagnosis, procedures performed and disposition was completed by clinicians. Alcohol use by the victims was determined by asking the victims if they took alcohol on that day or whether they were intoxicated during the violent event. The clinicians complemented this subjective assessment by checking for smell of alcohol from the victims during examination. In cases of multiple injuries, clinicians were asked to record the type and location of the three most severe injuries identified and document the total number of severe injuries the patient had sustained. At the end of each day, the data clerks collected all completed forms and 2 data clerks were assigned to enter the data daily onto a password protected Microsoft Excel 2010 spreadsheet. Ethical approval was obtained from the College of Medicine Research Ethics Committee to analyse the data.

\section{Data analysis}

The data was analysed using Stata Version 13.0. ${ }^{18}$ Univariate and bivariate analysis were done. Multivariate Logistic regression was used to determine characteristics associated with interpersonal violence. Variables included were age, gender, day of the week, season, location of injury and 
alcohol use in victims of interpersonal violence. Adjusted odds ratios were reported together with $95 \%$ confidence interval (CI). Results were considered to be statistically significant if the $\mathrm{p}$ value was less than 0.05 .

\section{Results}

Over the 2 year study period from May 2013 - May 2015, a total of $1,45,150$ cases were seen at the AETC. Out of these, 3,747 were trauma cases, representing $2.6 \%$ of all cases seen at the AETC.

Table 1: Results of univariate analysis describing general characteristics of the total population involved in an interpersonal violence event.

\begin{tabular}{|c|c|c|}
\hline $\begin{array}{l}\text { Interpersonal } \\
\text { violence } \\
\text { characteristics }\end{array}$ & Categories & $\begin{array}{l}\text { Frequency (\%) } \\
\mathrm{N}=1431\end{array}$ \\
\hline \multirow[t]{2}{*}{ Gender } & Male & $1137(79.5)$ \\
\hline & female & $294(20.5)$ \\
\hline \multirow{11}{*}{ Age categories } & 13-17 (children) & $60(4.2)$ \\
\hline & $18-19$ & $67(4.7)$ \\
\hline & $20-24$ & $273(19.1)$ \\
\hline & $25-29$ & $315(22.0)$ \\
\hline & $30-34$ & $270(18.9)$ \\
\hline & $35-39$ & $162(11.3)$ \\
\hline & $40-44$ & $100(7.0)$ \\
\hline & $45-49$ & $64(4.5)$ \\
\hline & $50-54$ & $43(3.0)$ \\
\hline & $55-59$ & $25(1.7)$ \\
\hline & $>60$ & $52(3.6)$ \\
\hline Assault location & Road & $532(37.2)$ \\
\hline \multirow[t]{8}{*}{ /setting } & Home & $483(33.8)$ \\
\hline & Work & $206(14.4)$ \\
\hline & Sports event & $66(4.6)$ \\
\hline & School & $21(1.5)$ \\
\hline & Farm & $4(0.3)$ \\
\hline & Public building & $31(2.2)$ \\
\hline & Other & $61(4.3)$ \\
\hline & Not recorded & $27(1.9)$ \\
\hline \multirow{3}{*}{$\begin{array}{l}\text { Injury } \\
\text { season }\end{array}$} & $\begin{array}{l}\text { Hot and dry (Aug- } \\
\text { Nov) }\end{array}$ & $477(33.3)$ \\
\hline & $\begin{array}{l}\text { Wet and rainy } \\
\text { (Dec-Apr) }\end{array}$ & $283(19.8)$ \\
\hline & $\begin{array}{l}\text { Cold and dry } \\
\text { (May-Jul) }\end{array}$ & $671(46.9)$ \\
\hline
\end{tabular}

Table 1 Cont....

Day of

Weekdays

$746(52.1)$

the week

Weekend

$665(46.5)$

Not recorded

$20(1.4)$

Assault

Bodily force

531 (37.1)

mechanism

Blunt objects

$392(27.4)$

Knife

$358(25.0)$

Gunshot/firearm

$1(0.1)$

Others

46 (3.2)

Unknown

$103(7.2)$

\section{Victims' No \\ use of alcohol Yes}

1186 (82.9)

$150(10.5)$

Not recorded

$95(6.6)$

\section{Perpetrator \\ of assault}

Stranger

806 (56.3)

Acquaintance

167 (11.7)

Domestic partner

288 (20.1)

Self-inflicted

94 (6.6)

Unknown

24 (1.7)

Not recorded

$52(3.6)$

Injury
type

Soft tissue injury

1061 (74.1)

Fracture

119 (8.3)

Dislocation

$16(1.1)$

Head injury

$17(1.2)$

Injury to internal organs

$9(0.6)$

Spinal injury

$2(0.1)$

Other

Not recorded

Disposition

Outpatient

1157 (80.9)

Admitted

$150(10.5)$

Deaths

$2(0.1)$

Not recorded

$122(8.5)$

$\mathrm{N}$ number of patients, $\%$ percent, $<$ less than and $>$ more than 
Among the trauma cases, 1431 patients were treated for interpersonal violence, representing $38.2 \%$ of all trauma cases recorded during this period. The majority of interpersonal violence cases occurred among male participants $(79.5 \%$ of all interpersonal violence cases) (Table 1). The most dominant age group was 25-29 year olds (22\%), while the least involved age group was 55-59 year olds (1.7\%). (Table 1)

Table 2: Results of univariate and multivariate logistics regression analysis showing risk factors associated with interpersonal violence

\begin{tabular}{|c|c|c|c|}
\hline Risk factor & & $\begin{array}{l}\text { Unadjusted } \\
\text { Odds Ratio } \\
(95 \% \mathrm{Cl})\end{array}$ & $\begin{array}{l}\text { Adjusted Odds Ratio } \\
(95 \% \mathrm{Cl})\end{array}$ \\
\hline \multirow[t]{3}{*}{ Season } & Hot \& dry & reference & \\
\hline & Cold \& dry & $0.80(0.68-0.94)$ & $1.26(1.08-1.47)^{*}$ \\
\hline & Wet \& rainy & $1.06(0.87-1.29)$ & $0.97(0.80-1.18)$ \\
\hline \multirow[t]{2}{*}{ Alcohol } & No & reference & \\
\hline & Yes & $1.70(1.33-2.16)$ & $1.63(1.27-2.10)^{*}$ \\
\hline \multirow[t]{4}{*}{ Location } & Other** & reference & \\
\hline & Work & $0.64(0.49-0.82)$ & $0.68(0.52-0.89)^{*}$ \\
\hline & Home & $1.41(1.13-1.78)$ & $1.62(1.27-2.06)^{*}$ \\
\hline & Road & $0.75(0.60-0.93)$ & $0.82(0.65-1.03)$ \\
\hline \multirow[t]{2}{*}{ Gender } & Male & reference & \\
\hline & Female & $0.97(0.82-1.14)$ & $0.82(0.69-0.98)^{*}$ \\
\hline \multirow[t]{3}{*}{ Age in Years } & $13-17$ & reference & \\
\hline & $18-49$ & $1.30(0.95-1.80)$ & $1.38(0.98-1.94)$ \\
\hline & $50-60$ & $1.20(0.79-1.82)$ & $1.26(0.81-1.97)$ \\
\hline \multirow{3}{*}{$\begin{array}{l}\text { Day of the } \\
\text { week }\end{array}$} & $>60$ & $0.78(0.48-1.25)$ & $0.74(0.44-1.22)$ \\
\hline & weekday & reference & \\
\hline & weekend & $0.85(0.74-0.97)$ & $1.12(0.97-1.29)$ \\
\hline
\end{tabular}

$*^{*}=$ significant at $0.05{ }^{* *}$ the location other includes schools, farm and public buildings

\section{Characteristics of interpersonal violence}

The most common places for interpersonal violence were on the road $(37.2 \%)$, at home $(33.8 \%)$ and at work place $(14.4 \%)$. Almost half $(46.9 \%)$ of the cases occurred in the cold and dry season and one in three cases (33.3\%) were in the hot and dry season. Majority of the cases $(46.5 \%)$ occurred during the weekend. Alcohol use was reported by $10.5 \%$ of the victims involved in interpersonal violence. (Table 1)

More than a third $(37.1 \%)$ of the cases were assaulted using bodily force which included kicks and punches with hands and feet. In $27.4 \%$ of the cases, blunt objects such as stones and metal bars were used as a weapon. There was only one case which was assaulted using a firearm. More than half $(56.3 \%)$ of the perpetrators were strangers to the victim and $11.7 \%$ of the cases were attacked by an acquaintance. Violence by a domestic partner occurred in $20.1 \%$ of the interpersonal violence cases. The remaining $11.9 \%$ of the cases were either self-inflicted or caused by an unknown perpetrator. Of all the domestic violence cases, three quarters of the victims were male $(76 \%)$ while female victims accounted for only a quarter of the cases $(24 \%)$. (Table 1)

The most commonly sustained injuries were soft tissue injuries such as lacerations, contusions and abrasions in $74.1 \%$ of participants. More serious injuries like fractures and head injury occurred in $8.3 \%$ and $1.2 \%$ of participants respectively. (Table 1). Of all the interpersonal violence trauma patients that arrived at the AETC, 80.9\% were treated as outpatients and sent home while $10.5 \%$ were admitted to the wards. There was one death on arrival and one died in the wards. (Table 1)

At multivariate regression analysis, those who had used alcohol during the violent event were 63\% more likely to be assaulted than those who did not use alcohol, (OR: 1.63; $95 \%$ CI: $1.27 ; 2.10$ ) and the risk of being assaulted was $18 \%$ less in women compared to men (OR: 0.82; 95\% CI: 0.69; 0.98). As compared to other places like schools, farm and public buildings, the odds of being assaulted were higher at home (OR: 1.62; 95\% CI: 1.27; 2.06) but lower at work (OR: $0.68 ; 95 \%$ CI: $0.52 ; 0.89)$ and on the road (OR: $0.82 ; 95 \%$ CI: $0.65 ; 1.03)$. The odds of being assaulted were higher in the cold and dry season (OR: 1.26; 95\% CI: 1.08; 1.47) but lower in the wet and rainy season (OR: 0.97; 95\% CI: 0.80; 1.18) as compared to hot and dry season. However, age, wet and rainy season, location of road and day of the week (whether it was a weekend or weekday) were not significantly associated with interpersonal violence as shown in table 2.

\section{Discussion}

Interpersonal violence is not addressed adequately in subSaharan Africa. Malawi, similar to other LIMCs, has a lack of published data on interpersonal violence and its related characteristics. In our study we found that trauma cases formed a minor part $(2.6 \%)$ of all the cases seen at the AETC of our hospital. This may be because our AETC treats more medical and surgical emergencies as compared to trauma. Also, minor trauma cases that are managed by a primary or secondary care facility or those who possibly died before seeking care are not recorded in our AETC registry.

Our study reported a high prevalence of interpersonal violence $(38.2 \%$ of all the recorded trauma cases). This is higher than a local study done in 2013, which reported that at Kamuzu Central Hospital, interpersonal violence accounted for $26.8 \%$ of all injuries. ${ }^{4}$ Our prevalence also surpasses what has been reported in other LMICs with similar characteristics 
to Malawi. For instance, in Uganda, a study by Mutto et al. found the prevalence of intentional injuries to be $22.2 \% .{ }^{19}$ While a study by Siedenberg et al. in Zambia reported that $20.0 \%$ of injuries were caused by interpersonal violence. ${ }^{20}$

Despite the fact that Malawi has never experienced any armed conflicts or civil strife, the prevalence of interpersonal violence is higher than those reported by other LMICs. This observation suggests that along with current or historical legacy of armed conflicts in a society, there are other factors driving the increased risk of interpersonal violence. This vast distribution of violence related injuries in LMICs may be related to a number of factors such as living, working and travelling in less safe conditions, less focus on prevention efforts in poorer areas, and poorer access to quality emergency trauma care and rehabilitation services. ${ }^{1,21}$

Data on risk factors for interpersonal violence is lacking in most of the African countries. Although studies conducted worldwide have repeatedly identified the high burden of interpersonal violence, less evidence exists regarding effective interventions for preventing interpersonal violence. The focus of this paper is on a population that has been traditionally neglected in the literature and using the ecological model, it highlights some population and environmental characteristics that are associated with interpersonal violence. This may help in identifying targeted interventions to reduce the burden of interpersonal violence in Malawi and other low and middle income countries.

There was male predominance $(79.5 \%)$ among the patients presenting with interpersonal violence related cases. The local study by Kiser et al. in 2013 specifically looked at sex differences in interpersonal violence and found that $78.7 \%$ of assault patients were males, ${ }^{4}$ a finding similar to our study. In 2012, over half a million individuals worldwide died as a result of injuries from interpersonal violence, of these deaths $81 \%$ were men. ${ }^{22}$ This high prevalence of male victims may be due to high rates of youth homicide which have been reported to be substantially lower among females. ${ }^{12}$ The male predominance can also be explained by the theories of gender norms, including norms and social constructions of masculinity which are likely the cause of most physical violence perpetrated by men against not only women but also against other men. These theories also state that men's violence is not simply about male dominance over women but can also be viewed as men establishing hierarchies among other men, hence the high levels of male victimization as seen in this study.

We also found that the dominant age-group involved was the 25-29 year olds, followed by the age group of 20-24 year olds. Youth violence is a global public health problem and it accounts for $43 \%$ of the total number of homicides globally each year among the age group of 10-29 years. ${ }^{23}$ A similar finding was observed in an assault-related injury report by Caselle et al in 2011. They found that case counts of interpersonal violence were highest among 20-24 year olds (34.3\%) followed by 15-19 year olds and 25-29 year olds with $26.1 \%$ and $23.6 \%$ respectively. ${ }^{24}$ The high rates of interpersonal violence among the adolescents and the young adults, as seen in our study, may be explained by the theory that the transition into adolescence begins the move towards independence from parents and young people may be attracted to violent behavior as a way of asserting their independence. ${ }^{25}$ Young adults, who are highly prone to violence, are more likely to be assaulted within their own neighborhoods. We found that the odds of being involved in interpersonal violence were significantly higher at home as compared to other locations. This may likely be due to the fact that young adults living in high density and poor urban townships are at a higher risk of trauma and violence and this was also seen to be the case in a study by Chokotho et al, who showed that high density locations were the hot spot locations for increased risk of trauma and injuries. ${ }^{26}$

There was also a significant association between interpersonal violence and season where the majority of interpersonal violence cases were in cold and dry season. This may be explained by the fact that during this season, days are shorter while the nights are longer making it dark earlier, therefore increasing the likelihood of interpersonal violence cases on the roads in the cold and dry season as compared to other seasons. Street lighting may improve visibility on the roads and hence lead to reduction in violent acts.

Intimate partner violence (IPV) is an important public health issue of global significance. Violence by domestic partners was reported in $20.1 \%$ of the cases in our study. We were surprised to find that three quarters consisted of male victims and only a quarter of the cases represented female victims. Traditionally, women have been considered to be the predominant victims and men the perpetrators of IPV hence most studies regarding IPV look at female victimization and the male victims of IPV have become an overlooked population. Worldwide, almost one third (30\%) of women who have been in a relationship report that they have experienced some form of physical and/or sexual violence by their intimate partner in their lifetime. ${ }^{27}$ Also, some of the highest global prevalence rates for intimate partner violence are in Africa. According to the global status report on violence prevention 2014, the prevalence of intimate partner violence in the African region was $36.3 \%{ }^{1}$ For countries with available data from demographic and health surveys (DHS); lifetime prevalence of women's physical and sexual abuse victimization was $64.1 \%$ in Democratic Republic of the Congo (DHS 2007), 42.3\% in Zimbabwe (DHS 2011) and 31.5\% in Mozambique (DHS 2011). In Malawi, Domestic violence, or IPV, is the most studied form of gender-based violence. ${ }^{28}$ According to the Malawi Demographic Health Survey (MDHS 2015-2016) and IPV 2005 survey, the prevalence of physical IPV was $34 \%$ and $30.1 \%$ respectively. ${ }^{29,30}$

The male preponderence in domestic violence noted in our study, maybe because women do not freely report cases of domestic violence. According to various surveys, the reasons so many cases go unreported are both personal (embarrassment, fear of retaliation, economic dependency) and societal (imbalanced power relations for men and women in society, privacy of the family, victim blaming attitudes). ${ }^{31}$

However, male victimization has not been studied sufficiently and therefore this issue of male victims in IPV needs to be explored further.

Despite the little attention that male victimization of IPV has received, women as perpetrators of IPV against their male partners has existed since the 1970s when IPV was first systematically examined. ${ }^{32}$ In 2010, a study in the United States looked at men who sustain intimate terrorism by women found that almost $80 \%$ of men participants reported that they were injured by their women partners, with $77.5 \%$ stating they sustained a minor injury and $35.1 \%$ sustaining a severe injury in the previous year. ${ }^{33}$ This same study also 
described some assumptions reported in previous studies which may be the reasons as to why women are perpetrators of IPV. A well-noted theory is of women acting solely in selfdefense or retaliation against their presumably violent men partners. However, other studies assessing women's motives for IPV showed that although some women reported selfdefense as a motive, most did not and men were clearly the victims of IPV. ${ }^{33}$

Nearly $11 \%$ of the victims in our study were intoxicated during the event of interpersonal violence. A local study reported a higher incidence of $16.5 \%$ alcohol use by victims of interpersonal violence. ${ }^{17}$ This can be explained by the fact that data on alcohol use were subjectively reported, hence it may represent under-reporting because blood alcohol levels are not routinely checked. Also the odds of alcohol usage could have been higher in the perpetrators than the victims of interpersonal violence. Caselle et al. in their assault-related injury report in Australia, used blood alcohol concentration (BAC) levels to determine alcohol use by victims and found that more than one-quarter were intoxicated or highly intoxicated at the time of assault. ${ }^{24}$ Therefore, there is need for objective testing methods like BAC derived from toxicology reports which can be used as a reliable method of measuring alcohol intoxication in victims.

In our study the odds of being assaulted, were higher in those participants who took alcohol, as compared to those who did not take alcohol during the violent event. Alcohol and interpersonal violence continue to challenge public health, and the link between the two has been recognized and repeatedly evidenced by many violence related studies worldwide. ${ }^{34,35}$ It is estimated to be responsible for $41 \%$ of male and $32 \%$ of female DALYs lost through homicide. ${ }^{34}$ There is also need to determine alcohol usage in perpetrators and its impact on interpersonal violence in our setting.

\section{Strengths and limitations of the study}

Some limitations are noteworthy in our study. Firstly some important characteristics associated with interpersonal violence, such as time of day when assault took place, education level and occupation of participants, which may have a major contribution to interpersonal violence, were not included in this study. This is because the data for this study was extracted from a database of trauma patients which focused on all forms of trauma rather than only interpersonal violence. Secondly, our study only captured data on patients that were managed at our AETC; therefore it was an underrepresentation of both; cases that were managed at a primary or secondary health care facility as well as those who possibly died before seeking care. Lastly, data on alcohol use by victims was subjectively reported, therefore there is need for objective testing methods of measuring alcohol intake in people involved in interpersonal violence. Despite these limitations, this study has a number of strengths; primary amongst them is the focus on a population that has been under-represented in world literature. In Malawi, most studies regarding interpersonal violence have been focused on gender-based violence. Therefore this study brings out the characteristics associated with interpersonal violence against both men and women, which has been under-studied in Malawi. Also, the data in this study was prospectively collected, forms were standardized and a large sample size was collected over a two year period, allowing us to assess impact of possible confounders and thus providing reliable data.

\section{Conclusion}

The majority of our participants involved in interpersonal violence were young males. Location of injury and seasonal variation were significant factors associated with interpersonal violence. Soft tissue injuries were the most common injuries sustained in interpersonal violence. These findings will help in identifying targeted interventions for interpersonal violence in Malawi and other LMICs.

\section{Conflict of Interest}

There are no known or perceived conflicts of interest

\section{Acknowledgement}

"We acknowledge the funding of the UK Department for International Development via the Tropical Health Education Trust for funding the trauma registry that was used for this paper, funded through the Health Partnership Scheme through the COSECSA Oxford Orthopaedic Link programme between College of Surgeons of East, Central and Southern Africa and University of Oxford."

\section{References}

1. World Health Organization (WHO). Global Status Report on Violence Prevention 2014. WHO. 2014. https://doi.org/10.1007/s13398-0140173-7.2

2. World report on violence and health: summary. Geneva, World Health Organization, 2002.

3. Matzopoulos, R., Bowman, B., Butchart, A., \& Mercy, J. A. The impact of violence on health in low- to middle-income countries. Int J Inj Contr Saf Promot. 2008; 15(4): 177-187. https://doi. org/10.1080/17457300802396487

4. Kiser, M., Escamilla, V., Samuel, J., Eichelberger, K., Mkwaila, J., Cairns, B., et al. Sex differences in interpersonal violence in Malawi: Analysis of a hospital-based trauma registry. World J Surg. 2013; 37(12): 2972-2978. https://doi.org/10.1007/s00268-013-2204-5

5. Bowman, B., Seedat, M., Duncan, N., Kobusingye, O. Violence and injuries. In Disease and Mortality in Sub-Saharan Africa. 2nd edition 2006. The International Bank for Reconstruction and Development/ The World Bank. https://doi.org/10.1596/978-0-8213-6397-3

6. World Health Organization (WHO). World Health Rankings violence death rate by country; 2017 [cited 2020 Feb 18]. Available from: http://www.worldlifeexpectancy.com/cause-of-death/violence/ by-country/

7. Ministry of Gender, Children, Disability and Social Welfare of the Republic of Malawi, United Nations Children's Fund, The Center for Social Research at the University of Malawi, and the Centers for Disease Control and Prevention. Violence against Children and Young Women in Malawi: Findings from a National Survey, 2013. Lilongwe, Malawi: Government of Malawi, 2014.

8. Long, S. J., Fone, D., Gartner, A., \& Bellis, M. A. Demographic and socioeconomic inequalities in the risk of emergency hospital admission for violence: cross-sectional analysis of a national database in Wales. BMJ. 2016; 6(8). http://dx.doi.org/10.1136/bmjopen-2016-011169

9. Geneva Declaration Secretariat. Global Burden of Armed Violence. Geneva; 2008.

10. The Institute for Economics and Peace (IEP). The Economic Cost of Violence Containment: A Comprehensive Assessment Of The Global Cost Of Violence; 2012. [cited 2020 Jan 12]. Available from: http:// economicsandpeace.org/wp-content/uploads/2015/06/The-EconomicCost-of-Violence-Containment.pdf

11. Institute for Economics and Peace (IEP). The economic impact of violence in South Africa; 25 March 2014. [cited 2020 Jan 12]. Available from: https://businesstech.co.za/news/general/54735/the-economicimpact-of-violence-in-south-africa/.

https://doi.org/10.4314/mmj.v32i1.6 
12. Krug, E. G, Dahlberg, L. L, Mercy, J. A., Zwi, A. B., \& Lozano, R World report on violence and health. World Health Organization. 2002. https://doi.org/10.1136/ip.9.1.93

13.Willman, A, Makisaka, M. Interpersonal violence prevention: a review of the evidence and emerging lessons. World development report 2011: Background Paper.World Bank; 2010.

14. Ember, C. R., Ember, M. War, socialization, and interpersonal violence: A cross-cultural study. J. Confl. Resolut. 1994 Dec; 38(4):62046. https://doi.org/10.1177/0022002794038004002

15.Hecker, T., Fetz, S., Ainamani, H., Elbert, T. The cycle of violence: Associations between exposure to violence, trauma-related symptoms and aggression-Findings from Congolese refugees in Uganda. J Trauma Stress. 2015 Oct; 28(5):448-55. doi: 10.1002/jts.22046.

16.Institute for Economics and Peace. Global Peace Index Snapshot: Measuring peace in a complex world; 2018. [cited 2020 Jan 12]. Available from: http://visionofhumanity.org/app/uploads/2018/06/ Global-Peace-Index-2018-Snapshot.pdf

17.Maine, R. G., Williams, B., Kincaid, J. A., Mulima, G., Varela, C., Gallaher, J. R., et al. Interpersonal violence in peacetime Malawi. Trauma Surg Acute Care Open. 2018 Dec 27;3(1): doi: 10.1136/ tsaco-2018-000252

18.StataCorp. (2013). Stata Statistical Software: Release 13. 2013. https://doi.org/10.2307/2234838

19.Mutto, M., Lett, R., Lawoko, S., Nansamba, C., \& Svanstrom, L. Intentional injuries among Ugandan youth: A trauma registry analysis. Inj. Prev. 2010; 16(5): 333-336. https://doi.org/10.1136/ip.2008.020495

20.Seidenberg, P., Cerwensky, K., Brown, R. O., Hammond, E., Mofu, Y., Lungu, J., et al. Epidemiology of injuries, outcomes, and hospital resource utilisation at a tertiary teaching hospital in Lusaka, Zambia. Afr J Emerg Med. 2014; 4(3): 115-122. https://doi.org/10.1016/j. afjem.2014.01.006

21.International Rescue Committee. Violence in the City: A Systematic Review of the Drivers of Violence against Displaced Populations in Urban Crisis and Post-crisis Settings; January 2017. [cited 2020 Feb 18]. Available from: https://www.rescue-uk.org/sites/default/files/ document/1290/violenceinthecityweb.pdf

22.Fleming, J., Gruskin, S., Rojo, F., Dworkin, L. Men's violence against women and men are inter-related: Recommendations for simultaneous intervention. US National Library of Medicine, National Institute of Health. 2015: 249-256. https://doi.org/10.1016/j. socscimed.2015.10.021

23.World Health Organization. Youth violence: Fact sheet; September 2016. [cited $2020 \mathrm{Feb} 18$ ]. Available from: www.who.int/mediacentre/ factsheets/fs356/en/.

24.Cassell, E., Reid, N., Clapperton, A., Houy-Prang, K., Kerr, E. Assault-related injury among young people aged 15-34 years that occured in public places: deaths and hospital treated injury. Victorian Injury Surveillance Unit (VISU). Hazard. Winter 2011; (Vol. 73).

25. Office of the Surgeon General (US); National Center for Injury Prevention and Control (US); National Institute of Mental Health
(US); Center for Mental Health Services (US). Risk Factors for Youth Violence. In Youth Violence: A Report of the Surgeon General; 2001. [cited 2019 Dec 20]. Available from: https://www.ncbi.nlm.nih.gov/ books/NBK44293/

26.Chokotho, L. C., Mulwafu, W., Nyirenda, M., Mbomuwa, F. J., Pandit, H. G., Le, G., et al. Establishment of trauma registry at Queen Elizabeth Central Hospital (QECH), Blantyre, Malawi and mapping of high risk geographic areas for trauma. World J Emerg Med. 2019; 10(1): 33-41. doi: 10.5847/wjem.j.1920-8642.2019.01.005

27.World Health Organization. Violence against women: Fact sheet; November 2017. [cited 2020 Feb 15]. Available from: http://www.who. $\mathrm{int} /$ mediacentre/factsheets/fs239/en/

28. Mellish, M., S. Settergren, Apuwa H. S. 2015. Gender-based Violence in Malawi: A Literature Review t o Inform t he Nat ional Response. W ashingt on, DC: Futures Group, Health Policy Project.

29. National Statistical Office (NSO) [Malawi] and ICF. 2017. Malawi Demographic and Health Survey 2015-16. Zomba, Malawi, and Rockville, Maryland, USA. NSO and ICF.

30. Pelser, E, Gondwe, L., Mayamba, C., Mhango, T., Phiri, W, Burton, P. Intimate Partner Violence: results from a National GenderBased Violence Study in Malawi. Crime \& Justice Statistical Division. National Statistical Office; December 2005. [cited 2019 Dec 29]. Available from: https://www.files.ethz.ch/isn/111749/ INTIMATEPARTNERVIOLENCE.PDF

31. Gracia E. Unreported cases of domestic violence against women: towards an epidemiology of social silence, tolerance, and inhibition. J Epidemiol Community Health. 2004 June 11: 536-537. doi:10.1136/ jech.2003.019604

32. Hines, D., Douglas, E. Women's Use of Intimate Partner Violence against Men: Prevalence, Implications, and Consequences. J Aggress Maltreat Trauma. 2009; 18(6): 572-586. https:/doi. org/10.1080/10926770903103099

33. Hines, D., Douglas, E. A Closer Look at Men Who Sustain Intimate Terrorism by Women. US National Library of Medicine, National Institute of Health. 2010: 286-313. https://doi.org/10.1891/19466560.1.3.286

34. Bellis, M., Hughes, K., \& Hughes, S. Alcohol and interpersonal violence: policy briefing. Geneva: World Health Organization. 2005: 1-22. https://doi.org/10.1016/j.bjoms.2010.11.003

35. The Centre on Alcohol Marketing and Youth (CAMY). Alcohol and Violence Fact Sheet; December 2015. [cited 2020 Feb 15]. Available from: http://www.camy.org/resources/fact-sheets/alcohol-violence/ index.html 